\title{
La apoesía
}

contemporánea: a

partir de los conceptos

de posautonomía e

\section{imaginación pública de Josefina Ludmer}

\author{
Contemporary Unpoetry: From Josefina Ludmer Concepts \\ of Post-autonomy and Public Imagination
}

A apoesia contemporânea: a partir do conceito de pós-

autonomia ea imaginação pública de Josefina Ludmer

\section{Alberto Pucheu}

UNIVERSIDADE FEDERAL DO RIO DE JANEIRO (UFRJ), BRASIL

Profesor del Programa de Posgrado en Letras (Ciencia de la Literatura), de la Universidade Federal do Rio de Janeiro. Doctor en Ciencia de la Literatura de la misma institución. Ha publicado los ensayos Pelo colorido, para além do cinzento: a literatura e seus entornos interventivos (Azougue; FAPERJ, 2007), Giorgio Agamben: poesia, filosofia, crítica (Azougue; FAPERJ, 2010), Antonio Cicero por Alberto Pucheu (EdUERJ, 2010), O amante da literatura (Oficina Raquel, 2010), Roberto Corrêa dos Santos: o poema contemporâneo enquanto o ensaio teórico-críticoexperimental (Azougue, 2012). Correo electrónico: apucheu@gmail.com

Artículo de reflexión

El presente ensayo forma parte del proyecto en curso "Poesia e contemporaneidade: no e de fora do atual", financiado por la Beca de Productividad en Investigación del Conselho Nacional de Desenvolvimento Científico e Tecnológico (CNPq) y por el programa "Cientista del nosso Estado", de la Fundação de Amparo à Pesquisa do Estado do Rio de Janeiro (FAPERJ).

Traducción de Maria Cândida Ferreira de Almeida y María de los Ángeles Aldana (graduada de Literatura y Filosofía de la Universidad de los Andes, Bogotá; correo electrónico: md.aldana57@uniandes.edu.co).

Documento accesible en línea desde la siguiente dirección: http://revistas.javeriana.edu.co 


\section{Resumen}

Este artículo parte de la propuesta que hace Ludmer en el marco de la pregunta por la literatura: el pensamiento especulativo, por medio de la imaginación pública, lleva a la literatura a su posautonomía. Sin embargo, este texto va más allá al proponer una forma radical de literatura posautónoma, que excede a la lengua y se remonta a una dimensión subterránea: la facultad del lenguaje. Con este paso, se logra quebrantar las limitaciones de la lengua en su identificación con un territorio nacional.

Palabras clave: poesía, literatura, lenguaje, territorio.

Palabras descriptor: Poesía moderna, literatura moderna, lenguaje, territorio.

\section{Abstract}

In this article, the author takes Ludmer's contribution in the context of the question of literature: speculative thought, through the public imagination takes literature to its postindependence. However, the text goes further by proposing a radical form of post-autonomous literature that surpasses language and goes back to an underground dimension: the power of language. With this step, the author manages to break the limitations of language in its identification with a country.

Keywords: poetry, literature, language, territory.

Keywords plus: Poetry, modern literature, language, territory.

\section{Resumo}

Este artigo parte do aporte feito por Josefina Ludmer no marco da pergunta pela literatura: $o$ pensamento especulativo, por meio da imaginação pública, leva a literatura a sua pós-autonomia. No entanto, este texto vai além ao propor uma forma radical de literatura pós-autónoma, que excede à língua e remonta a uma dimensão subterrânea: a faculdade da linguagem. Com este passo, se consegue romper as limitações da língua em sua identificação com um território nacional.

Palavras-chaves: poesia, literatura, linguagem, território. Palavras-chave descritores:

Poesia moderna, literatura moderna, língua, território.

RECIBIDO: 3 DE MARZO DE 2013. EVALUADO: 25 DE ABRIL DE 2013. ACEPTADO: 25 DE ABRIL DE 2013.

\section{Cómo citar este artículo:}

Pucheu, Alberto. "La poesía contemporánea: a partir de los conceptos de posautonomía e imaginación pública de Josefina Ludmer". Cuadernos de Literatura 18.35 (2014): 211-225. 
BUSGANDO DIRECGIONAR LA evolución de la autonomía a la posautonomía, Josefina Ludmer parte de la concepción de la literatura como "lente, máquina, pantalla, mazo de tarot, vehículo y estaciones para poder ver algo de la fábrica de realidad" (Aquí 12). En una entrevista, ella aclara:

Empecé a pensar de una forma borgeana: que la literatura era más real que la realidad. Al leer, lo que se cuenta es real. La idea de especulación -el género especulativo, que imagina realidades, como la ciencia ficción- me apareció junto con la idea de literatura como realidad. Es una crítica a la posición de la crítica literaria, que se atribuye a la literatura. La idea de imaginación pública tiene que ver con que estamos sumergidos en discursos, imágenes, y que eso es con lo que se construye la realidad. ("La crítica")

Ludmer parte, por tanto, de este "más real que la realidad" para llegar a la propia realidad, y convierte el arte y la realidad en algo indiscernible.

La preposición del término posautonomía (que dialoga explícitamente con la heteronomía de su amiga Florencia Garramuño) no quiere indicar una superación final que, instaurando el aislamiento de un nuevo tiempo, acabaría de una vez con las actuaciones que comprenden a la literatura y al arte en su autonomía; sin dejarse encajar en los registros binarios. El pos prepositivo demanda una nueva posibilidad en la esfera de lo cotidiano y de la creación, que viene a confrontar una dinámica de superposición sincrónica en la que lo autónomo y su pos, al contrario de que cada uno aniquile a su alteridad, dejan sus camadas visibles en transparencias actuantes, como en una acuarela anónima y pública en la que las superposiciones de las imágenes diacrónicas se mantienen ambivalentes, y borran la cronología y la obligatoriedad de la existencia de solo uno de los planos. El tiempo hace converger las variaciones históricas para la diferencia de un ahora (en el que el arcaico se aproxima a nosotros con más fuerza) acogedor de las más distintas temporalidades que se presentan en movilidades de constelaciones, series, redes y superposiciones que se agregan y desagregan, posibilitadoras de otras lecturas del pasado y del presente.

En Aquí América Latina, parte de la "especulación", como un pensamiento en imagen de inspiración benjaminiana, considerada por ella como un género literario (10) y una ficción (una ficción literaria especulativa que, ampliando los procedimientos críticos, agrega la imaginación y el afecto al concepto, y termina creando un bloque indiscernible o en fusión: imaginativo-conceptual-sensible). La teoría ficcionista establece exactamente lo que denomina literaturas posautónomas; crea entonces el concepto de imaginación pública para referirse al momento en el que cierta experiencia de lo que ya fue llamado de literatura, en 
armonía con otras esferas de su tiempo, alcanza el fin del ciclo de la autonomía literaria iniciado por Kant y por la modernidad, se encuentra en conexión con los otros discursos y llega a su propio fin.

Josefina Ludmer se adentra en la literatura para, desguarneciendo las fronteras, sobrepasarla, en dirección a los territorios de la imaginación pública. Entonces, si, como se ha indicado, "la literatura [es] más real que la realidad", "la ficción cambia de estatuto porque abarca la realidad hasta confundirse con ella" (Aquí 10), para que la vitalidad flagrada en ella o en lo poético esté fundida con todo y cualquier acontecimiento, con todo y cualquier lugar. En uno de los textos del libro, "Literaturas posautónomas", Ludmer escribió:

Las literaturas posautónomas del presente saldrían de la "literatura", atravesarían la frontera, y entrarían en un medio (en una materia) real-virtual, sin límites, la imaginación pública: en todo lo que se produce y circula y nos penetra y es social y privado y público y "real". O sea, entrarían en un tipo de materia y en un trabajo social (la realidad cotidiana) en que no hay "índice de realidad" o "de ficción" y que construye el presente. Entrarían en la fábrica del presente que es la imaginación pública [...]. ("Literaturas")

Por otra parte, en el fin de la literatura, entendida a partir de su autonomía, la imaginación pública sería un proceso inmanente de conectividad total, en una amplia dimensión del lenguaje para fundir los diversos usos de las lenguas como el conjunto de las producciones inmateriales (eletrónica-geográfica-económicasocial-cultural-política-filosófica-religiosa-jurídica-estatal-acfetiva-corporalerótica-de-género-y-sexo-cotidianas...), en el que la diferencia entre ficción y realidad quedaría suspendida en la experiencia de la fábrica de realidad como realidad-ficción.

Ludmer toma las narrativas de los inmigrantes latinoamericanos como paradigmáticas y creando con ellas los conceptos de territorio de la nación, territorio de la lengua e imperio, y es sobre todo en la tensión de estos dos últimos que su pensamiento se singulariza más al quebrar el obstáculo entre lengua y territorio nacional. Esto ocurre exactamente porque el inmigrante pierde su territorio nacional y sufre el quiebre entre nación y lengua, en la que pasa a habitar. Esto hace que la lengua -con la nación perdida- sea su patria desterritorializada en el territorio de la lengua (como ya querría Bernardo Soares al afirmar que "mi patria es la lengua portuguesa" [Pessoa 225]). Se forma así una comunidad transnacional:

El territorio de la lengua es uno de los centros de la fábrica de realidad y uno de los instrumentos conceptuales para pensar los años 2000 en América 
Latina. Él contiene a la literatura, pero la traslada. Es un hecho de palabras (dichas, oídas, miradas, leídas, recordadas) y de todo lo que circula en nuestro idioma: radios, periódicos, revistas, teléfonos, celulares, Internet, call centers, locutorios, blogs, chats, libros, traducciones, manuales, gramáticas, diccionarios, enciclopedias... (Ludmer, Aquí 188)

A esto habría que añadir aun documentos, diarios, biografías, autobiografías, testigos, cartas, e-mails, crónicas, reportajes periodísticos e innumerables posibilidades que, más allá de las dicotomías, mezclan lo íntimo y lo público, lo real y lo ficcional.

Con todos aquellos modos en que circula el idioma, ahora transterritorializado, es en la lengua campo de opresión sin opresor, con sus sentidos coercitivamente dados, que se hace el nuevo proceso de subjetivación y de discusión con el mundo del inmigrante. $\mathrm{O}$, aún peor, campo o territorio de la lengua con un opresor, ya que el concepto teórico-ficcional de "imperio" funciona para dar cuenta de la fuerza verticalmente jerárquica de las instituciones soberanas de control de la lengua que quieren mantener su hegemonía más allá del territorio nacional, en una unidad que a toda costa quiere ser preservada y domesticada. En lo que respecta a la lengua española o castellana que interesa a Josefina Ludmer, cuyo control proviene de España, instituciones como la Real Academia Española, el Instituto Cervantes y la Asociación de las Academias de Lengua Española, unidas a vastas empresas transnacionales del libro que determinan lo que debe ser escrito, publicado y leído, intentan cumplir el objetivo de regular el uso de la lengua para apoderarse del individuo hasta que, carente este de su singularidad, logren dominarlo hasta donde sea posible. Lo que el "imperio" desea con su biopoder es, en la nulidad del deseo que construye singularidades, llevar al individuo a identificarse con él, la sumisión máxima del individuo al "imperio", que tiende a negar los valores particulares y los deseos singulares en nombre de un universal absoluto formado por las estrategias favorables a la manutención disciplinar. Se preserva así el control de la lengua -y de lo que considera consecuente- como uno de los focos principales de su biopolítica, de su reglamentación y producción de la vida social. Una muestra del control institucional de la lengua que presenta Aquí América Latina es, por ejemplo, el paso de recurso natural a recurso económico en el español de nuestro continente a partir de los años noventa:

Porque, para llegar al imperio desde la lengua, hay que imaginar primero el pasaje de "recurso natural" a "recurso económico" y esto ocurre en América Latina desde los años 1990. Dice José del Valle, cuyos trabajos son 
imprescindibles en este punto: hacia los años 1990 los empresarios españoles hablan de "el potencial económico del español" y muestran la dimensión económica de la lengua con títulos o nombres como "econometría de la lengua española", "el mercado de las lenguas". Grupos y asociaciones como Asociación para el Progreso del Español como Recurso Económico y su sucesora Eduespaña promueven el español como lengua de encuentro, como lengua global y como recurso económico que produce 15\% del PIB de España. Del Valle marca la mentalidad empresarial del capitalismo neoliberal en la lengua y al mismo tiempo "la vieja unión colonial". Y eso es crucial desde aquí para imaginar el territorio de la lengua como territorio imperial. (190)

Si el libro privilegia que la biopolítica del "imperio" se establezca como consecuencia de la soberanía del territorio de la lengua (único "aterrizaje" del emigrante), es preciso que se instaure un movimiento de circulación que, en su horizontalidad móvil, coopere con la posibilidad del descentramiento del viajante de la diáspora, del emigrante, del extranjero. Es necesario que la lengua también se desancle en un cierto proceso de emigración, de salida, de exilio, de deportación y, en ese desprendimiento de la lengua al salir del territorio propio, sería preciso que, al contrario de lo que escribió Bernardo Soares, la lengua no fuera más nuestra patria. Para que el territorio de la lengua no se deje apresar por la dimensión imperial ni por las posibilidades económicas del mercado privado, en la actualidad, en el mundo neoliberal, mucho más veloz y determinante incluso que las políticas estatales, es preciso garantizar una desterritorialización radical, es decir, de toda y cualquier lengua. De este modo sería posible hacer una resistencia al imperio con lo que queda de inaprensible, con lo que permanece no apropiable. En la anterior cita, con la idea de realizar una crítica del paso de la lengua a recurso económico e imperial en los años noventa, Josefina Ludmer entiende la lengua o el idioma como recurso natural. Esa parece ser de hecho su tónica:

Especular desde aquí en el territorio de la lengua es usar una teoría naturalista del lenguaje (una teoría del subsuelo y del suelo del humano, que nos une a todos), que es una teoría de lo no expropiable. Especular con otra biopolítica: con lo que nos iguala a los seres humanos porque todos somos hablantes $\mathrm{y}$, por lo tanto habitantes y sujetos del territorio de la lengua (del castellano somos unos 400 millones y 100 más que lo hablan como segunda lengua). El primer postulado entonces es que en el territorio de la lengua no hay dueños porque el lenguaje (en tanto facultad e idioma) es un recurso natural, un anexo y un complemento de los cuerpos, como la tierra, el agua (o el petróleo) 
o el aire. El lenguaje es una facultad que ocupa algo así como el subsuelo biológico de lo humano; es preindividual y el medio para la individuación. Pero los recursos naturales de todos y de nadie de América Latina (nuestros complementos como los ríos, las montañas y la lengua misma) se transforman en recursos económicos y son objeto de apropiación y explotación por parte del capitalismo global, como dice el colectivo Wu Ming. Porque la lengua no es solo un recurso natural, sino el medio de producción de los medios de comunicación, y las cosas hechas de lengua (la patria del emigrado) forman parte de una industria global y un mercado, y son uno de los centros de la producción inmaterial de hoy. (Aquí 189)

Debido a que su texto está enfocado en América Latina, momentáneamente, en busca de una otra biopolítica, de modo que no se vuelva al territorio geográfico sino al territorio de la lengua, la teórica argentina articula una teoría naturalista del lenguaje. Compara tanto el lenguaje en cuanto facultad como, indiferenciadamente, la lengua en cuanto idioma para recursos naturales como la tierra, el agua, los ríos, las montañas, el petróleo, el aire. Justamente por esa naturalización de la lengua y del idioma, hace que sean pensados al tiempo que la nueva territorialidad del emigrante que, alejado de su nación, se asienta en el idioma patrio territorializado y naturalizado, a la vez que la lengua materna lo funde dentro de sí. En el caso del castellano, la primera lengua de 400 millones de personas y la segunda de más de 100 millones, lleva su apropiación a través del imperio, la industria global y el mercado.

Así, es momento de proponer algunas cosas. ¿Es posible una "teoría naturalista" del lenguaje que, en busca de "lo que nos une a todos", de lo que "nos iguala a los seres humanos porque somos todos hablantes", no distinguiría la facultad del lenguaje que caracteriza al ser hablante del idioma? ${ }_{\mathrm{d}}$ Es posible una "teoría naturalista" del lenguaje que sea, indistintamente, una teoría de lo subterráneo y del suelo humano? O, dentro de la tipología anunciada, ¿necesitaríamos de un corte entre lo subterráneo (el lenguaje como facultad del ser hablante, como su transcendental, por el hecho de que el ser hablante habla) y el suelo (la lengua, el idioma, lo que habla el ser hablante)? ¿ ¿La lengua y el idioma pueden ser naturalizados o tal papel cabría exclusivamente a la facultad del lenguaje del ser hablante, fracturada en su relación con la lengua o con el idioma? Para que, como quiere Josefina Ludmer, tal territorio de la lengua no pueda ser poseído de modo alguno por los dueños, ¿no sería preferible entenderlo como un territorio de la facultad del lenguaje?, mejor dicho, ¿cómo pensar la facultad del lenguaje en tanto desterritorialización siempre disponible, incluso del idioma, aunque sus hablantes seríamos, en algún grado, huérfanos? Sin el corte entre facultad del 
lenguaje y lengua o idioma, sin el corte entre subterráneo y suelo, ¿no se caería en nuevas bipolaridades que Josefina Ludmer quiere y consigue superar tan bien, instigándonos? Naturalizando la lengua (en este caso, la española -pero también cualquier otra-) o situándola como subterránea, ¿itendríamos una restricción primera (la retirada de Brasil de la América Latina que, a pesar del título del libro, hasta podría ser comprendida ya que no se trata más de un territorio geográfico, sino de un territorio de la lengua) y otras más amplias (la de la división del mundo entre el territorio lingüístico de los que hablan el español y los territorios lingüísticos de los que hablan otras lenguas), "en lo que nos une a todos", en el hecho de ser "todos hablantes"? ¿No caeríamos en nuevas segregaciones que dividirían con fronteras a los seres hablantes en territorialidades idiomáticas, preservando la segregación que había geográficamente en las nuevas territorialidades de las lenguas diversas? ${ }_{\mathrm{d}}$ Podremos buscar un pensamiento de lo subterráneo de la facultad del lenguaje y al tiempo lo que de hecho nos une a todos como seres hablantes? Entiendo Aquí América Latina como un paradigma que me impulsa y me conduce más allá o, tal vez, a la propia América Latina. Me hace pensar que estoy transitando en una zona suspendida en la que no sé más lo que es de Josefina Ludmer y lo que, a partir de la admirable firma de su pensamiento, aquí se escribe. Tal vez exista una zona en suspensión entre la estrategia empleada por la perspectiva teórica para alcanzar el fin que le interesa y la estrategia usada para el fin que este ensayo quiere lograr. El pensamiento posautónomo de la literatura debe encontrarse, aquí, con un pensamiento posterritorializado de la lengua y, por tanto, aun con un pos-o-más-allá-o-más acá-de la-América Latina.

Lo que "que nos une a todos" y "nos iguala a los seres humanos porque somos todos hablantes", lo que hay de natural y de común es la facultad del lenguaje, no el idioma. El ser humano no tiene el idioma por naturaleza, lo tiene por cultura, por tanto es contingente, exógeno. Lo que tenemos por naturaleza es apenas la posibilidad de que cada uno de nosotros sea hablante de cualquier idioma que aprendamos; solo el hecho de potencialmente poder aprender cualquier idioma. Nacemos desprovistos del idioma que llegamos a hablar, pero con la facultad de poder aprenderlo (o cualquier otro que recibamos de fuera de nuestro cuerpo, por fuera de lo que en nosotros es natural o endógeno). Es esto lo que Agamben quiere decir cuando, en la elaboración de su concepto de infancia, afirma que "en el hombre se produjo una separación entre la disposición para el lenguaje (o estar listos para la comunicación) y el proceso de actualización de esta virtualidad" (Infância 73). La disposición para el lenguaje, la potencia para el lenguaje, es lo que en nosotros es natural, mientras que la actualización de esta virtud en el aprendizaje de cualquier idioma sucede con respecto a actores cul- 
turales, exógenos. Se puede decir que el ser humano, en tanto que político y ético, es el articulador de esa diferencia y de la resonancia recíproca que en ella existe. Aquello que nos iguala no es el idioma específico aprendido, sino la disposición o la potencialidad de llevar a cabo el aprendizaje de cualquier idioma. Agamben -cuando discurre sobre lo "que nos une a todos" y lo que "nos iguala a los seres humanos porque somos todos hablantes" - atiborra nuestra dimensión política, ética, cultural y ontológica para exigir una nueva teoría de la subjetividad y de lo común; se trata de una experiencia del lenguaje en su existencia, la experiencia de la cosa del lenguaje "en cuanto al lenguaje, no de esta o de aquella proposición significante, sino del solo hecho [de] que se hable, de que haya lenguaje" (Agamben, Infância 12). Para Agamben, esa es la "virada" primordial de nuestro tiempo, el corte que, desde el aprendizaje necesario con el nihilismo llevado a las últimas consecuencias, instaura el presente en su diferencia respecto al pasado:

Así, finalmente, nos encontramos solos con nuestras palabras, por primera vez solos con el lenguaje, abandonados de todo fundamento ulterior. Esta es la revolución copernicana que el pensamiento de nuestro tiempo hereda del nihilismo: somos los primeros hombres que se han vuelto completamente conscientes del lenguaje. Aquello que las generaciones pasadas han pensado como Dios, ser, espíritu, inconsciente, por primera vez nosotros lo vemos límpidamente como lo que son: nombres del lenguaje. Por eso toda filosofía, toda religión y todo saber que no hayan tomado conciencia de este viraje, pertenecen para nosotros irrevocablemente al pasado. Los velos que teología, ontología y psicología han tendido sobre el humano han caído ahora y uno a uno nosotros los restituimos a su lugar propio en el lenguaje. Sin velos miramos ahora al lenguaje, que ha expelido de sí a todo lo divino, a todo indecible: enteramente revelado, absolutamente en el principio. ("L'idée" 37-38)

Volviendo a Josefina Ludmer, considero que sus conceptos más necesarios son los que desnaturalizan el idioma y lo dejan flotar en una zona inestable que, llevada a resonar, nos remonta a la potencialidad del lenguaje, lo que permite leer, en una nueva mirada, las diversas experiencias cotidianas de este, suspendiendo, con la contrafuerza de su agramaticalidad, en algunas líneas de fuga detectables, la concepción dominante de la literatura en su autonomía; y, aún más, subvirtiendo la del imperio con su gramática hegemónica transnacional y la del mercado globalizado. En Aquí América Latina, el territorio de la lengua es uno de los centros de la fábrica de realidad que es la imaginación pública, esta sí desnaturalizada, sin centro fijo, puro movimiento inestancable que no deja ningún centro en la garantía de su deseo de inmovilidad. Creada por ese pensamiento imaginario 
llamado especulativo, la imaginación pública se ubica en una entreterritorialidad articuladora de las tensiones existentes entre las preservaciones jerárquicamente institucionales o "imperiales" de una lengua transnacionalmente territorializa$d a$, que se concibe unificada, y las diferencias desterritorializantes que establecen a la lengua por medio de los dispositivos de poder del lenguaje, mientras que la potencia del decir conserva su apertura en todo dicho, en relación con toda y cualquier lengua, que resguarda una anterioridad o una posterioridad a toda literatura. La imaginación pública, el espacio autopoético necesario de interconexión compleja entre las territorializaciones y las desterritorializaciones de la lengua, en la cual una literatura también se desintegra y deja su autonomía, y tanto las subjetividades como la realidad son constantemente producidas a partir de la maleabilidad que se percibe, es el concepto especulativo por excelencia de Aquí América Latina. Cabe aquí citar lo que señala Ludmer sobre el término en la introducción del libro:

La especulación inventa un mundo diferente del conocido: un universo sin afueras, real virtual (la virtualidad es el elemento tecnológico), de imágenes y palabras, discursos y narraciones, que fluye en un movimiento perpetuo y efímero. Y en ese movimiento traza formas. Lo llama imaginación pública o fábrica de realidad: es todo lo que circula, el aire que se respira, la telaraña y el destino. La imaginación pública sería un trabajo social, anónimo y colectivo de construcción de realidad. Todos somos capaces de imaginar, todos somos creadores (como en el lenguaje igualitario y creativo de Chomsky), y ninguno es dueño. Así especula la especulación desde América Latina.

En el lugar de lo público, se borra la separación entre el imaginario individual y el social; la imaginación pública, en su movimiento, desprivatiza y cambia la experiencia privada. Lo público es lo que está afuera y adentro, como íntimopúblico. En la especulación nada queda solo adentro: el secreto, la intimidad y la memoria se hacen públicas.

La imaginación pública fabrica realidad pero no tiene índice de realidad, ella misma no diferencia entre realidad y ficción. Su régimen es la realidad ficción, su lógica es el movimiento, la conectividad y la superposición, sobreimpresión y fusión de todo lo visto y oído. Esa fuerza creadora de realidad, la materia de la especulación, funciona según muchísimos regímenes de sentido y es ambivalente: puede darse la vuelta o usarse en cualquier dirección. (Aquí 11-12)

En plena movilización inestancable y total conectividad, sobrepuestas y fundidas, sin límite, la realidad es imágenes efímeras, anónimas, íntimas-públicas. Tales palabras e imágenes componen, mientras "fuerzan", la fábrica de realidad 
de la imaginación pública a la cual, en lo cotidiano mismo, en una política de lo cotidiano, en lo cotidiano que es político, ningún "imperio" es capaz de sobreponerse completamente. Por ella, en lugar de los escritores llamados hiperliterarios (105) (que insisten "todo el tiempo en decir "soy literatura", y utilizan "todo tipo de marcas literarias: personajes escritores, personajes lectores, autorreferenciales y referenciales a la literatura. La escrita dentro de la escrita, la literatura dentro de la literatura, la lectura dentro de la lectura" [87]), Josefina Ludmer persigue a los que desestabilizan las marcas internas, autorreferenciales, de la parafernalia estructurada por los modos narrativos de lo literario en su autonomía, y realizan un gesto de salir de la literatura sin dejar de estar en ella; a los que realizan "un gesto fuera-dentro", "un ya no más al mismo tiempo que un aún" (107); a los que ya "no admiten lecturas literarias; eso quiere decir que no se sabe o no importa si son o no son literatura. Y tampoco se sabe o importa si son realidad o ficción. Se instalan localmente en una realidad cotidiana para fabricar el presente y ese es precisamente su sentido" (149).

Es posible entonces que en ese rumor de las diversas voces y múltiples medios sobrepuestos, por donde transita el amontonamiento de los infinitos discursos que todos los seres humanos son aptos para imaginar; que en esta política y en esta ética en que la vida está, cotidiana e inestablemente siendo desechada y la realidad está siendo construida, "se pueda dar la vuelta al mundo" (192). Es posible entonces que el tiempo de la vida cotidiana solo pueda ser definido en negativo, "como el otro y el que no es", y lo cotidiano, "el concepto filosófico que designa lo no filosófico, el concepto literario que designa lo no literario, el concepto histórico que designa lo no histórico", sea "un tiempo roto, hecho de interrupciones y fracturas" (40). Es posible entonces que, en esa confusión del lenguaje en un solo tiempo personal, suprapersonal y anónimo, en ese murmullo del común, consigamos oír algo del nuevo mundo, algo de la contemporaneidad. Es posible entonces que lleguemos a tener el lugar del lenguaje como materia de la "especulación" crítica y creadora para liberar el sentido en el lugar de su nacimiento. Es posible entonces que tal confusión, al tener lugar, no pueda ser representada por ser el espacio mismo del nacimiento de toda representación. Es posible entonces que lidiemos con "una palabra-idea, que sea al mismo tiempo abstracta y concreta, individual y pública, subjetiva y social, epistemológica y afectiva" (17). Es posible, por tanto, que la potencia de la poesía se extravíe de su autonomía -ya que no proveniente de ella-, multiplicándose, mientras lucha, por el dentro-fuera del murmullo de esa palabra-idea de Josefina Ludmer. Como una aventura para la cual nuestro tiempo, siempre incompleto y fuera de los ejes, se muestra apto. 
En lo que dice Ludmer con respecto a lo que se escribe en el vector posautonómo de la literatura, se trata de, como ya mencioné, desestabilizar las marcas internas, autorreferenciales, de la parafernalia estructurada por los modos narrativos de lo literario. $\mathrm{O}$, dicho de otro modo, de borrar los "parámetros que definen lo que es literatura", los "criterios o categorías literarias", todo lo que asegura las "identidades literarias", "la especificidad y atributos literarios", "las marcas de pertenencia a la literatura", a la "literaturalidad" ("Literaturas"). Entre otras, nociones como las de autor, obra, verosimilitud, simulacro, géneros, movimientos, corrientes, clasificaciones, estilo, sentido y metáfora (y también la densidad, la paradoja, la inefabilidad...) reciben tal operación de desvanecimiento que, para Josefina Ludmer, ya no se puede leer más tales textos como literatura.

Tal vez porque el punto de partida de Aquí América Latina es el interés en la ficción latinoamericana y, más decisivamente, en la ficción argentina de los años 2000, Josefina Ludmer recalca que la preservación de ciertas marcas literarias, como el formato libro, el nombre del autor, la inserción mayor o menor en el mercado y en otros modos que avalan y canonizan (procesos editoriales selectivos, premios, ferias nacionales e internacionales, estudios académicos, reseñas o apariciones en los medios, exposición en librerías, etc.) no son suficientes para destituir tales escrituras de su lugar de posliteratura, en la medida en que alcanzan lo que le parece ser de mayor importancia, la destitución del "valor literario": Las escrituras posautónomas pueden exhibir o no sus marcas de pertenencia a la literatura y a los tópicos de autorreferencialidad que marcaran la era de la literatura autónoma: el hito, las relaciones especulativas, el libro en el libro, el narrador como escritor y lector, las duplicaciones internas, recursividades, similitudes, paralelismos, paradojas, citas y referencias a autores y lecturas (aunque sean en tono burlesco, como en la literatura de Roberto Bolaño). Pueden situarse o no simbólicamente dentro de la literatura y seguir ostentando los atributos que las definían antes, cuando eran totalmente "literatura". O pueden clasificarse como Basura (Héctor Abad Faciolince. I Premio de Narrativa Americana Innovadora, Casa de las Américas. Madrid, Lengua de Trapo, 2000) o Trash (Daniel Link. La ansiedad: novela trash. Buenos Aires, El Cuenco de Plata, 2004). Eso no cambia su estatus de literaturas posautónomas. Tanto en sus posiciones como en sus matices, esas escrituras presentan el problema del valor literario. ("Literaturas") 
Impulsado por Josefina Ludmer, pero sin estar en este momento específico interesado en mantener lo que habitualmente es llamado literatura, aunque deje al descubierto modalidades escritas de la contemporaneidad, me gustaría aventurarme adonde ella misma no llegó. Me gustaría, con ella, ir más allá de ella: con los conceptos de pos-autonomía de la literatura e imaginación pública se puede resaltar y especular un tipo de escritura-imagen-idea que, luego de frente, abandone radicalmente los cuatro pilares primordiales que continúan ubicándose como preponderantes, y se vuelven más difícil de apropiar por los poderes institucionales: el formato libro (en cualquier soporte que sea -papel, archivos virtuales u otros-), la obra, el nombre del autor y el mercado. Y que, además, saliendo del "cerco literario, donde estaba limitada por principios literarios", ella no se contenta simplemente con, moviéndose en otros caminos, encontrarse con "una investigación histórica, una biografía, una crónica, un testimonio" ("A literatura" 23), una autobiografía, una entrevista, una autoficción, una memoria. Necesita ir aún más lejos. Y que, además, no participe de los medios que avalúan, consagran, canonizan y promocionan la literatura, sin someterse a ellos y sin recibir de ellos, en ninguna instancia, una coerción que los lleve a la sumisión. Y que, además, deje de lado completamente los "parámetros que definen lo que es literatura", los "criterios o categorías literarias", todo lo que asegura las "identidades literarias", "la especificidad y atributos literarios", "las marcas de pertenencia a la literatura", la "literaturalidad". No deja de ser apropiada por cuestiones de género o clasificaciones literarias, ni por el hegemónico "realismo sentimental de las telenovelas" o por ningún tipo de tentativa de copia más o menos directa de la realidad. Y que, además, no tome absolutamente en cuenta la lógica de las películas y libros de acción, que no trace tiempos muertos ni vacíos para posibilitar el pensamiento crítico y afectivo del espectador o del lector. Y que, además, rompiendo el hilo de la literatura, venga directo, anónima y colectivamente, de la imaginación pública, fabricando la realidad. Y que, además, sea una escrituraimagen-idea que, realizada por un anónimo cualquiera, por sujetos ausentes, retirados, sin firmas, de los cuales no se sabe a qué grupo, a qué familia o a qué clase pertenecen, hable, por la visibilidad de la intervención que se arriesga a tener, para todos y para nadie; tocando, afectando y atravesándonos en nuestras diferencias, sin poner atención a las divisiones de nación, clase, sexo, identidades (personales, locales, globales, culturales); quedando apenas con lo común de un territorio desterritorializado, de algunas lenguas para formar la imaginación pública, en un grado tan intenso y vivo como el de la literatura en su fuerza, pero, de hecho, por fuera de lo que la constituye en cuanto que institución. Y que, además, no realiza absolutamente nada que nos remita a una dimensión expresiva de cualquier 
supuesta interioridad individual creadora; no es un obstáculo para la circulación de su modo discursivo, en ese caso, de su escritura-imagen. Y que, además, escribiendo sin escritura y pintando sin pintura, burle la franja de segregación entre la cultura llamada erudita, la cultura llamada popular y la imaginación pública. Asimismo, a lo que no quiera hacer parte de ningún sistema estético convencional. Es una escritura-imagen-idea que, dando visibilidad pública a su profanación, sobreponga, en ese gesto político, la voz del anónimo común, del cualquiera; lo que hay de exclusivamente privado, de estatal y de imperial, sin privilegiar asuntos reforzados por la literatura de mayor vendaje de los últimos años, que me gustaría que aún fueran transgresores, como el tráfico, las drogas, la violencia, la marginalidad, la policía heroica o corrupta, experimentos sexuales, el sujeto con sus narrativas... Además, en ese gesto político de poner una marca de imagen, palabra y pensamiento en el lugar de lo privado y de lo estatal, ella, "ensuciando" (desde el punto de vista supuestamente aséptico de estos) lo privado y lo estatal, sea sin ley, es decir, ni autónoma ni heterónoma, sino únicamente anónima. Que su política sea de lo cotidiano y su cotidianidad sea ya política. Así, bajo la certeza de su breve desaparición, nazca su forma bajo el impulso de aquello que la destruirá en los próximos momentos. Y que, además, sin exigir un gesto más o menos solitario del libro, de la sala de cine, de la sala de teatro, del museo, de la galería, del cuarto (o de la sala), del escritorio o de la biblioteca, de la librería, del bar, de las inmensas arenas públicas para conciertos... ella encuentre y se mantenga, en medio del camino de cualquiera, en plena ciudad abierta, actuando no en los espacios resguardados en que se dan las atracciones principales, sino reivindicando su interacción con cualesquiera otros acontecimientos cotidianos, por entre los que se desliza. De modo que, acatando el juego dispersivo de los transeúntes, ella se inserte en medio de lo cotidiano por intensidades imprevisibles, avalando y destruyendo la categoría de espectador. Y que, además, sin solicitar una inserción en alguna totalidad espacial de la ciudad, asuma el carácter meramente fragmentario del espacio que utiliza y lo transforme. Nacida de lo cotidiano, ni atrasada ni adelantada en relación con nada, ni en la vanguardia ni en la retaguardia de nada, contemporánea, traiga, aunque sin necesidad de saber, la inscripción de lo antiguo en la materialidad de su superficie. Y que, con esto, accione diversas imágenes prehistóricas, diversos gestos de escritura y pintura de varios tiempos históricos, diversas lenguas históricas, tenidas por muertas y en ella revivificadas, todas fundidas en la materialidad de su superficie. Y que con sus espacios indeterminados, con sus lenguas desterritorializadas, con sus paisajes urbanos casi sin paisajes, con sus restos y ruinas de paisajes ilocalizables, ella no sea de aquí (del Brasil o de la América Latina), o de allá (de Portugal, de 
España, de Europa o, en una palabra, del polo preponderante del imperialismo moderno, sobre todo hasta el siglo XIX), ni de más allá (del foco dominante del imperialismo norteamericano, preponderante en el siglo XX). Que ella no sea literatura ni antiliteratura, pero que sea capaz de dejar su propio recuerdo en su posicionamiento anónimo de caer en el olvido. Por lo tanto, me lleva a no saber si es o no lo que se puede llamar literatura o poesía. Que ella sea sin libro, sin autoría, sin género, sin nación, sin ciudad, sin barrio, sin dinero, sin mercado, sin consagración, sin evaluación previa, sin los medios de comunicación de masa... Que ella sea sin. Que ella sea. Apoesía. Contemporánea.

\section{Obras citadas}

Agamben, Giorgio. Infância e história. Trad. Henrique Burigo. Belo

Horizonte: Universidade Federal de Minas Gerais (UFMG), 2005.

Agamben, Giorgio. "L'idée de langage". La puissance de la pensée; essais e conférences. Buenos Aires: Adriana Hidalgo, 2007. 37-38.

Ludmer, Josefina. Aquí América Latina: una especulación.

Buenos Aires: Eterna Cadencia, 2010.

Ludmer, Josefina. "Literaturas pós-autônomas". 2010. Web. $<$ http://www.culturaebarbarie.org/sopro/outros/posautonomas.html>.

Ludmer, Josefina. "La crítica pura me aburre". 23 de octubre de 2011. Web. <http://josefinaludmer.wordpress.com/>.

Ludmer, Josefina. "A literatura não é mais sagrada. Entrevista a Rachel Bertol". Valor Económico 12.580 (diciembre de 2011): 20-24.

Pessoa, Fernando. Livro do desassossego. Composto por Bernardo

Soares, ajudante de guarda-livros na cidade de Lisboa. Ed.

Richard Zenith. São Paulo: Companhia das Letras, 2001. 